2006

\title{
Allostasis, Homeostasis, and the Costs of Physiological Adaptation
}

Sarah C. Coste

Linfield College

Follow this and additional works at: https://digitalcommons.linfield.edu/hhpafac_pubs

Part of the Biology Commons, and the Physiology Commons

\section{DigitalCommons@Linfield Citation}

Coste, Sarah C., "Allostasis, Homeostasis, and the Costs of Physiological Adaptation" (2006). Faculty Publications. Published Version. Submission 6.

https://digitalcommons.linfield.edu/hhpafac_pubs/6

This Published Version is protected by copyright and/or related rights. It is brought to you for free via open access, courtesy of DigitalCommons@Linfield, with permission from the rights-holder(s). Your use of this Published Version must comply with the Terms of Use for material posted in DigitalCommons@Linfield, or with other stated terms (such as a Creative Commons license) indicated in the record and/or on the work itself. For more information, or if you have questions about permitted uses, please contact digitalcommons@linfield.edu. 


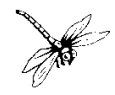

GENERAL BIOLOGY

Allostasis, Homeostasis, and the Costs of Physiological Adaptation.

Edited by Jay Schulkin. Cambridge and New York: Cambridge University Press. \$100.00. xii + 372 p; ill.; index. ISBN: 0-521-81141-4. 2004.

The concept of homeostasis is a fundamental, organizing principle of regulatory physiology that has long been used to explain the primal function of physiological systems-to maintain constant or static conditions of the internal environment. This concept is taught in nearly every introductory chapter of biology and physiological textbooks, and has served us well in understanding basic physiological function. Inherent weaknesses of this concept have emerged over the years as scientists have attempted to cohere their findings with this principle. It is now generally accepted that the internal environment is not constant, but rather "set points" can change and adapt in response to external challenges, seasonal variation, or ecological demands. For some, such incongruity has warranted the need for a new framework to integrate physiological function with our new understanding of physiological plasticity.

This volume introduces the emerging concept of allostasis and describes its meaning and biological use within the context of homeostasis. Allostasis was conceived by the neurobiologist Peter Sterling and the epidemiologist Joseph Eyer in 1988 to convey the importance of the brain-body relationship in regulating the internal milieu. They define allostasis as stability through change where an organism must vary parameters of its internal milieu and match them appropriately to environmental demands. In this model, central coordination by the brain plays a critical role in overriding local negative feedback mechanisms and imposing new set points in response to anticipated or existing external demands. The models go on to suggest that such continuous adjustments to achieve or maintain new set points that match demand a biological burden or "wear and tear" on the body, a phenomena termed allostatic load. This concept is argued as useful in linking bodily adaptation and vulnerability to disease. It is hoped that the operationalization of allostatic load will aid in prediction and assessment of various pathophysiologies.

The volume begins with an intriguing chapter by the founder of the term, Peter Sterling. The remaining chapters are contributions by prominent 
researchers who have embraced the concept of allostasis and integrated it into their research. The final chapter is an interesting commentary that provides critical analysis of the concepts presented in the book. Collectively, the volume represents a diverse field of scientific research, ranging from anxiety and drug addiction to chronobiology, and, thus readers are given broad examples for the use of this emergent concept. Because each chapter is mutually exclusive from the others, authors begin with a description of the conception and utility of allostasis and allostatic load from their perspective. This is a weakness of the book, as it is redundant at times. Although there is general agreement among the authors, there are subtle variations that readers are left to discern. It is important to note that none of the contributors argue for the abandonment of homeostasis, rather they propose there is room and necessity for both concepts in understanding physiological regulation.

This book is intended for graduate-level students and researchers who study behavioral and physiological processes. It is certainly thought provoking and will likely convince readers that allostasis should become a concept taught side by side with homeostasis.

SARAH C Coste, Microbiology E Immunology, Oregon Health and Science University, Portland, Oregon 